\title{
EXTENDING A RESULT OF HAYNSWORTH
}

\section{QIAN LI, QINGWEN WANG AND SHENG DONG}

Abstract. Haynsworth [4] refined a determinant inequality for two positive definite matrices. We extend Haynsworth's result to more than two positive definite matrices and obtain some inequalities for sum of positive definite matrices. Moreover, we show some generalizations of these to sector matrices.

Mathematics subject classification (2010): 15A45, 47A63.

Keywords and phrases: Determinant inequality, Haynsworth's inequality, sector matrices.

\section{REFERENCES}

[1] X. FU, Y. LIU AND S. LU, Extension of determinantal inequalities of positive definite matrices, Journal of Mathematical Inequalities 11 (2017), 355-359.

[2] A. George And Kh.D. IKramov, On the properties of Accretive-Dissipative Matrices, Math. Notes. 77 (2005), 767-776.

[3] D.J. HartFiel, An extension of Haynsworth's determinant inequality, Proc. Amer. Math. Soc. 41 (1973), 463-465.

[4] E.V. Haynsworth, Applications of an inequality for the Schur complement, Proc. Amer. Math. Soc. 24 (1970), 512-516.

[5] L. Hou And S. Dong, An Extension of Hartfiel's determinant inequality, Math. Inequal. Appl. 21 (2018), 1105-1110.

[6] R.A. Horn And C.R. Johnson, Matrix Analysis, 2nd ed., Cambridge University Press, Cambridge, 2013.

[7] M. LIN, Fischer type determinantal inequalities for accretive-dissipative matrices, Linear Algebra Appl. 438 (2013), 2808-2812.

[8] M. LIN, A determinantal inequality for positive definite matrices, Electron J. Linear Algebra 27 (2014), 821-826.

[9] M. Lin, Extension of a result of Hanynsworth and Hartfiel, Arch. Math. 1 (2015), 93-100.

[10] M. LIN, Some inequalities for sector matrices, Operators and Matrices 10 (2016), 915-921.

[11] M. Lin AND D. ZHOU, Norm inequalities for accretive-dissipative operator matrices, J. Math. Anal. Appl. 407 (2013), 436-442.

[12] F. Zhang, Matrix Theory, Basic results and techniques, Second Edition, Springer, (2011). 